\title{
Factors Affecting Academic Performance of Undergraduate Students: Evidence from a Public University in Bangladesh
}

\author{
Mohammad Jahangir Alam ${ }^{1 *} \quad$ Mst. Fatema Khatun ${ }^{2}$ \\ 1. Assistant Professor, Department of Accounting and Information Systems, Jashore University of Science and \\ Technology, Jashore, Bangladesh \\ 2. Research Student at Department of Accounting and Information Systems, Jashore University of Science and \\ Technology, Jashore, Bangladesh
}

\begin{abstract}
Academic result measured by Grade Point Average is often considered as the most dominant performance indicator of a student in most of developing countries like Bangladesh. Several prior studies have been conducted to determine the factors which act as control measures to the academic performance in tertiary level education. But the obtained results varied largely depending on the socio-economic context and education policy of the nations. The study aims at finding out the factors that affect the academic performance of students of a public university situated in the south-western part of Bangladesh and to assess the relative predictability of various factors on academic performance. A sample of 314 graduate students from different disciples was chosen based on a random sampling method. Principal Component Analysis (PCA) as a statistical tool has been used to extract factors affecting academic performance. Multiple Linear regression was run to predict the influence of these factors on the dependent variable. The academic factor that includes conventional exam system, teachers' evaluation system, and academic study environment appeared as the most dominant determinant factors affecting academic performance. Other important factors such as the financial condition of students, family income, social media affiliation, part-time job, extra-curricular activities also dictate academic performance. Regression coefficient indicates that gender, higher secondary examination grades, sleeping duration, academic study hours have a significant influence on academic achievement. The study results will be useful to the students, academicians, guardians of the students, policymakers, and researchers to have a better understanding of determinants of academic achievement and taking appropriate measures accordingly.
\end{abstract}

Keywords: Academic performance, PCA, Academic factors, demographic and socio-economic factors, Public university students, Bangladesh.

DOI: $10.7176 / \mathrm{JEP} / 12-5-07$

Publication date: February $28^{\text {th }} 2021$

\section{Introduction:}

Academic grading measured in Cumulative Grade Point Average (CGPA) has become an indicator of the performance measurement of students in most nations of the world. GPA is being used as a primary assessment tool to reduce the number of competitors in the highly demanding job market in the Indian Sub-continent, particularly in Bangladesh. Students with higher GPAs usually get more opportunities in their entry to education and employment (Ainscow et al., 2006; Hudley \& Duran, 2013). Most of the Universities around the world seek students with good academic results as the entry-level performance indicator for Masters and $\mathrm{PhD}$ level education. GPA as a performance measurement criteria has been used by most researchers around the world (AL-Mutairi, 2011). Academic performance creates quality leadership and manpower which is vital to the socioeconomic development of a country (Ali et. al, 2009). Empirical evidence shows that academic achievement is affected by several factors based on the socio-economic condition and development index of a country. Researchers around the world identified socio-economic and demographic factors, institutional environment and support factors, teaching quality, motivational factors, extra-curricular activities, social media affiliation, sleeping duration, the academic vision of the country, etc. as the parameters of academic success. Bangladesh is a developing country and its tertiary education is mostly controlled by government-funded colleges and universities and 107 private universities under the University Grand Commission of Bangladesh. Bangladesh is a country where, CGPA is being considered as the indicator of students' quality in school, college, and university level admission process. Higher grades became the predominantly required criteria for most of the job recruitment process in Bangladesh. But, the Research on the determinants of the academic performance in tertiary level education in Bangladesh is scant. Hence, the present study finds enough scope to explore the determining factors of academic achievement of the undergraduate students in tertiary level education in Bangladesh. The researchers also focused on the nature and level of influence of these factors on academic performance. Therefore, the objectives of the study are: (i) to determine the influencing factors which affect the academic performance of university students of Bangladesh, (ii) to determine the level of agreement of the respondents on the factors obtained, (iii) to predict the influence or relationship of these factors on academic performance. 


\section{Literature Review and Hypotheses}

An extensive review of prior studies on factors affecting students' academic performance reveals some interesting findings. Researchers around the world explored the different predictors of academic performance based on demographic variables, socioeconomic status (SES), sleeping duration, academic study environment, parental education, income level, social media affiliation, age, gender, income level, and many more. Family background of students, study habits, home-related issues, school facilities, and teachers' effectiveness have a significant association with the academic performance of students' (Olufemioladebinu et al., 2018). Alhajraf \&. Alasfour (2014) identified gender, age, high school GPA, and high school major as determining factors of academic achievement. Demir (2009) found evidence that family background and the students' quality have a strong influence on the students' academic achievement and students' characteristics including gender, grade, work status, well-being at school, scholastic activities, and parental support have a large variance with the academic performance. Tastan et al. (2017) showed that gender has no significant effect on academic performance but nationality has a great influence on academic performance in science education. They also exerted that teacher's efficacy and motivation have a positive association with academic performance. A Study pursued by Alam et al. (2014) on the performance of undergraduate students in Bangladesh revealed that gender, age, medium of education, past academic records, and class percentage have a significant influence on performance. Sakız \& Aftab (2019) showed that academic achievement differs based on socio-demographic aspects, namely school type and income level. A case study conducted on the students of Islamic University Subcampus in Pakistan by Ali et al. (2013) arrived at the conclusion that academic performance is affected by various factors such as age, gender, schooling, faculty of study, guardian /father socio-economic status, medium of schooling, residential area, study hours, tuition trend, and accommodation trend. Hijazi and Naqvi (2006) identified a positive correlation of academic performance with attendance in class and mother's education; and a negative correlation with family income, study hour, and mothers' age. Considine \& Zappala (2002) found that gender, parents' education, unexplained absences, housing type, student age, and ethnicity are statistically significant predictors of academic performance.

Some researchers emphasized that the Socio-economic Status (SES) of students is the prime predictor of academic performance. Farooq et al. (2011) carried out a case study on the secondary school level in Pakistan and concluded that academic achievement is strongly related to SES and parental education. Eamon (2005) concluded that the students who came from low SES or areas show low performance. Pedrosa et al. (2006) concluded that the parent's good socio-economic condition is the catalyst to better performance. A recent study by Prabhakaran \& Suresh (2020) on SES and related influence on academic achievement of the students in Tamilnadu, India revealed that economic support, academic needs, academic decisions, and financial interdependence as the dominant predictors in academic performance. A study on junior high school students in China by Shifeng et al. (2020) reveals that both self-concept and family SES were significantly associated with mathematics and Chinese performance. Yinusa and Basil (2008) identified parental income, family type, and the funding systems of the government as the predictors of academic performance.

Researchers in the present days are trying to assess the level of influence of social media and media sharing networks such as Facebook, Twitter, LinkedIn, Instagram, Snapchat, YouTube, etc. on academic performance. Celestine \& Nonyelum (2018) found a significant negative relationship between academic performance and time spent on social media. Gorhe (2019) found both positive and negative influence of social media on performance. He deduced that careful use of media is not harmful, but the unconscious use is detrimental to academic performance. The Study conducted by Mensah and Nizam (2016) also reveals the same findings.

Some researchers focused on the sleeping duration of students to measure the level of impact on academic performance. Kelly et al. (2001) reported that short sleepers have significantly lower overall GPAs than long sleepers did. Raley et al. (2016) showed that sleeping duration is positively associated with academic results. Results obtained from their study indicate that students with grades of 3.5 or higher reported an average sleeping duration of 6.47 hours before examination and students with grades 3.00 or less reported an average duration of 6.47 hours.

Learning facility, overall learning environment, teaching style, and efficacy also got priority as predictors of academic performance. Mushtaq \& Khan (2012) found learning facilities, communication, proper guidance, and family stress as the influencing factors of academic performance. The study identified family stress as negative motivators in academic performance.

Arora \& Singh (2017) showed that study habits, educators' teaching efficacy, and the family environment of the participants as significant predictors of the academic achievement of college students. Results also pointed out significant differences in academic performance based on gender. Ahmed \& Salim (2018) identified that previous results, department type, teacher-student relationship, gender, class percentages, self-confidence, depression, and credit hours taken are the predictors of academic achievement in private universities in Bangladesh. Raychaudhuri et al. (2010) concluded that student's class attendance, parents' education, family income, teacher-student ratio, trained teachers in school, gender, and distance of schools are the important 
factors that have a positive relationship with academic achievement. This study also found evidence that high attendees are more serious in studies than low attendees. Mohamed et al. (2018) found that academic achievement is affected by some specific variables such as study habits, home-related aspects, learning techniques, and physical resources. Singh et al. (2016) concluded with the statement that communication skills, learning facilities as well as appropriate guidance by parents have a significant positive association with academic achievement.

Students' motivation and individual expectations are vital parts of acquiring sound academic performance (Nayebzadeh et al., 2013). Nationality has also been used by AL-Mutairi (2011) as a predictor of academic performance and observed that the performance of non-national students is better than native students. The researchers developed the following hypotheses considering the different attributes derived from the study context and existing literature review.

$\boldsymbol{H}_{1}$ : There is no relationship between gender and academic performance.

$\boldsymbol{H}_{2:}$ There is no relation between secondary level (SSC and HSC) results and academic performance at the tertiary level.

$\boldsymbol{H}_{3}$ : There is no relation between monthly family income and academic performance.

$\boldsymbol{H}_{4}$ : There is no relation between the sleeping duration of students and academic performance.

$\boldsymbol{H}_{5}$ : There is no relation between academic study hours and academic performance.

$\boldsymbol{H}_{6}$ : There is no relation between factors 1 (academic issues - Conventional Exam System, Teacher's Evaluation System, University Academic Environment) and academic performance.

$\boldsymbol{H}_{7}$ : There is no relation between Factor 2 (Poor Financial Condition and family monthly income) and academic performance.

$\boldsymbol{H}_{8}$ : There is no relation between Factor 3 (Social Media and Co-curriculum activities, Tuition or Parttime Job, Residence Area) and academic performance.

\section{Data and Methodology}

\subsection{Sample selection and data collection}

The study aimed at finding out the influencing factors which determine the academic performance of university students in Bangladesh. In this pursuit, 314 respondents out of approximately 1700 graduates of a public university named Jashore University of Science and Technology (JUST) were chosen using random sampling in which students from science, business, and humanities disciplines were included. Data has been collected through a questionnaire survey in January and February 2020 during the office hours of the university opening days. Some questionnaires were distributed to both the resident and non-resident students and collected accordingly.

The questionnaire comprised structured and some open-ended questions. The questionnaire was divided into three sections based on the objectives of the study. The first section of the questionnaire comprised of demographic and socio-economic variables. The second section comprised questions of relative perception of the respondents measured on a 5-point Likert-scale ranging from 1 (strongly disagree) to 5(strongly agree). These questions have been selected for this section based on extensive literature review; consultations with professional social science researchers and academic experts.

The third section of the questionnaire comprised the open-ended questionnaire to have opinions on the additional variables which may affect the academic achievement of students.

In addition to that, secondary data were collected from various scholarly books, journals, articles, published materials, survey reports, internship reports, newspapers, and online web content.

\subsection{Variable Identification and analysis technique}

All the descriptive and inferential statistics results were computed using SPSS version 25.0 for windows. Data collected through questionnaire were coded properly and checked for missing or outliers in data and found appropriate for analysis. Demographic and socio-economic variables are coded as variable1 (V1) to variable 5 (V5) and variable 8 (V8) to variable 18 (V18). Likert-type data were coded as variable 19 (V19) to variable 26 (V26) for extracting factor components (latent variables) which determines the academic performance of students. All other required tests through SPSS were conducted to verify the suitability of data for Principal Component Analysis (PCA). Means of the factors have been used to measure the level of satisfaction of the respondents on the factors obtained from PCA. Multiple Linear Regression was run to assess the predictability of various socio-economic and Likert-type variables on academic performance. Students' CGPAs obtained at their graduation level was used as the dependent variable and nine categorical and continuous variable has been used as the independent variable. 


\section{Empirical Results and Discussions}

4.1 Descriptive statistics of the demographic and socio-economic variables:

Among the tested samples, 55.1 percent were male and 44.9 percent female. 67.80 percent of the participants belong to the science group, whereas the percentage of graduates from the business studies group and arts groups were 21.30 percent and 10.80 percent respectively. Since the sampled university is a Science and Technology University, its science graduates are predominantly larger than other disciplines. The university provides housing facilities to the students but it is not a fully resident university. The percentage of resident students is 54.8 and the rest of the respondents reside outside of campus. Interestingly, fathers are the main bread earner of the family ( 90.1 percent) of most of the students. Analysis of parents' profession reveals that 34.1 percent is engaged in various government and non-government services; 27.1 percent are farmers; 24.8 percent engaged in business and 14 percent are self-employed and engaged in other income-generating activities. It is interesting to notice that 92 percent of mothers of the respondents are housewives and only 7.3 are engaged in services. Parents' educational status shows that 34.1 percent of fathers of the respondents have undergraduate and above level education and $11.8 \%$ have no formal education. Only 15.3 percent of mothers, on the other hand, have undergraduate and above level education. Most of the mothers have a Secondary School Certificate (51.9 percent). 59.6 percent of parents' have a monthly family income of less than twenty thousand Taka (Bangladeshi currency) and 20.1 percent have a monthly family income of less than Taka 10,000. The mean Grade Point Average (GPA) of SSC and HSC of the respondents are 4.93 (out of 5) and 4.80 (out of 5) respectively. The mean GPA of the graduates in this study is 3.28 (0ut of 4).

\subsection{Results and discussions on Factor Analysis (EFA-PCA):}

The Likert-scale data related to factors affecting academic performance were examined through PCA with the 'Varimax with Keiser Normalization' method using SPSS. The initial inspection of the R-matrix indicated a sufficient number of coefficients above 0.30. The KMO measure of sampling adequacy was 0.66, that exceeds the required value of 0.60 (Kaiser, 1970) and Bartlett's Sphericity test (Bartlett, 1954) shows statistical significance $(\mathrm{p}<.001)$, assured that coded data are suitable for Factor Analysis.

Table 1: KMO Sampling Adequacy and Bartlett's Test

\begin{tabular}{llc}
\hline KMO Sampling Adequacy. & & .66 \\
\hline Bartlett's Test of Sphericity & Approx. Chi-Square & 400.54 \\
& df & 28 \\
& Sig. & .00 \\
\hline
\end{tabular}

The Principal Component analysis (PCA) was run with Varimax rotation and the results in Table-2 revealed three latent factors with no communalities less than .30 and Eigenvalues greater than 1, explaining $22.9 \%$, $19.97 \%$, and $19.22 \%$ respectively considering Rotation Sums. The cumulative variance explained is $62.10 \%$ which is sufficient to explain the factors which determine the performance.

Table 2: Extracted factors and Total Variance Explained

\begin{tabular}{|c|c|c|c|c|c|c|c|c|c|}
\hline \multirow{4}{*}{ Component } & \multicolumn{9}{|c|}{ Total Variance Explained } \\
\hline & \multicolumn{3}{|c|}{ Initial Eigenvalues } & \multicolumn{3}{|c|}{$\begin{array}{c}\text { Extraction Sums of Squared } \\
\text { Loadings }\end{array}$} & \multicolumn{3}{|c|}{$\begin{array}{c}\text { Rotation Sums of Squared } \\
\text { Loadings }\end{array}$} \\
\hline & & $\%$ of & & & $\%$ of & & & $\%$ of & \\
\hline & Total & Variance & Cumulative $\%$ & Total & Variance & Cumulative $\%$ & Total & Variance & Cumulative $\%$ \\
\hline 1 & 2.33 & 29.06 & 29.06 & 2.33 & 29.06 & 29.06 & 1.83 & 22.91 & 22.91 \\
\hline 2 & 1.61 & 20.06 & 49.13 & 1.61 & 20.06 & 49.13 & 1.60 & 19.97 & 42.88 \\
\hline 3 & 1.04 & 12.98 & 62.11 & 1.04 & 12.98 & 62.11 & 1.54 & 19.22 & 62.11 \\
\hline 4 & .79 & 9.93 & 72.04 & & & & & & \\
\hline 5 & .72 & 9.02 & 81.05 & & & & & & \\
\hline 6 & .61 & 7.56 & 88.61 & & & & & & \\
\hline 7 & .51 & 6.42 & 95.03 & & & & & & \\
\hline 8 & .40 & 4.97 & 100.00 & & & & & & \\
\hline
\end{tabular}

Note: Extraction Method: Principal Component Analysis

The researcher applied the best-practiced criteria for factor retention and table- 3 shows 8 factors with three latent components. Three items (Conventional Exam System, Teacher's Evaluation System, and University Academic Environment) were loaded on factors 1; two items (Poor Financial Condition, and Higher monthly family income) on factor 2; and three items (Social Media and Co-curriculum activities, Tuition or Part-time Job, and Residence Area) on factor 3. 
Table 3: Factors Loadings of the variables in different components Rotated Component Matrix

\begin{tabular}{lccc}
\hline & \multicolumn{3}{c}{ Factor Component } \\
\cline { 2 - 4 } & $\begin{array}{c}\text { Academic } \\
\text { factors (1) }\end{array}$ & $\begin{array}{c}\text { Parents' financial } \\
\text { condition (2) }\end{array}$ & $\begin{array}{c}\text { Non-academic } \\
\text { issues (3) }\end{array}$ \\
\hline Poor Financial Condition & .738 & .893 & \\
Conventional Exam System & .809 & & \\
Teacher's Evaluation System & .733 & & .606 \\
University Academic Environment & & & .767 \\
Social Media and Co-curriculum activities & & .886 & .702 \\
Tuition or Part time Job & & & \\
Residence Area & & & \\
Higher monthly family income & & & \\
\hline
\end{tabular}

Analysis of table 3 and the derived Scree plots indicate that factor relating to academic issues (factor 1) is the most dominant factor that controls the academic achievement of students. Items loaded in this factor includes conventional exam system, teachers' evaluation system, and university academic environment. The Reliability Statistics through Cronbach's Alpha $=.68$ and mean inter-item correlation $=.41$ implies a strong internal consistency among the items loaded in the factor.

Parents' financial condition (factor 2) loaded as the second important factor. It is interesting to note that, this factor is a highly loaded factor which indicates that most of the respondents are in agreement that the poor financial condition of students acts as a hindrance on the performance at tertiary level and higher family income positively affect academic performance. Cronbach's Alpha $=.73$ and mean inter-item correlation $=.59$ of this factor indicates a strong internal consistency among the items and ensures an acceptable level of reliability.

Non-academic issues such as time spent on social media or extra-curricular activities, tuition or part-time job to meet the educational expense, residential status loaded as third important for which determines the academic performance. The Cronbach's Alpha $=.51$ and mean inter-item correlation $=.26$ of this factor indicates an acceptable level of internal consistency among the items. The reliability test result has been summarized in the following table.

Table 4: Cronbach's Alpha Reliability and Inter-item correlations

\begin{tabular}{lcccc}
\hline \multicolumn{1}{c}{ Factors } & Alpha & $\begin{array}{c}\text { Alpha Based on } \\
\text { Standardized Items }\end{array}$ & $\boldsymbol{N}$ & $\begin{array}{c}\text { Inter-Item } \\
\text { Correlations }\end{array}$ \\
\hline Academic Issues (1) & .675 & .675 & 3 & .409 \\
Parents' financial condition (2) & .731 & .742 & 2 & .589 \\
Non-academic issues (3) & .514 & .514 & 3 & .261 \\
\hline
\end{tabular}

4.3 Results on the level of satisfaction on the factors obtained

The means score as obtained from the factors through SPSS gives a clear picture on the level of agreement of the respondents on the factors obtained as shown in the table 5.

Table 5: Mean (M) and Standard Deviation (SD) of extracted factors

\begin{tabular}{lccc}
\hline \multicolumn{1}{c}{ Factors } & $\boldsymbol{N}$ & $\boldsymbol{M}$ & $\boldsymbol{S D}$ \\
\hline Academic Issues (1) & 314 & 3.42 & .89 \\
Parents' financial condition (2) & 314 & 3.05 & .99 \\
Non-academic issues (3) & 314 & 3.15 & .85 \\
\hline
\end{tabular}

The mean score of factor 1 is 3.42 and SD is .89 respectively which indicates that respondents are satisfied with the argument that academic issues are the most dominant factor in determining the academic grades of students in tertiary level. Analysis of the mean and SD of factor 2 and factor 3 shows a satisfactory mean and lower SD which indicates that parents' financial conditions and non-academic issues also determines the academic performance of student under study.

\subsection{Result of Multiple Linear Regression and hypotheses testing}

Multiple linear regression was used to assess the level of influence of the nine control measures (gender, SSC results, HSC results, monthly family income, sleeping duration, study hours, and three-factor components from PCA) on the performance of students' measures in terms of CGPA. The primary analysis was conducted through SPSS to ensure the suitability of data to run multiple linear regression. Normality, linearity, multi-collinearity, and homoscedasticity were tested and found no violation of assumptions in this process. The model summary of the regression analysis is shown in table 6. 
Table 6: Variable explained in regression analysis

\begin{tabular}{ccccc}
\hline \multicolumn{5}{c}{ Model Summary $^{\mathrm{b}}$} \\
\hline Model & $R$ & $R^{2}$ & ${\text { Adjusted } R^{2}}$ & $S E$ \\
\hline 1 & $.806^{\mathrm{a}}$ & .65 & .639 & .18363 \\
\hline
\end{tabular}

a. Predictors: (Constant), mean score of factor 3, Academic Study Hours, mean score of factor 2, Sleeping Duration of Students, Monthly Family Income, Male or Female, S.S.C result, mean score of Factor 1, H.S.C result

b. Dependent Variable: Academic Performance measured in CGPA

The adjusted $\mathrm{R}$ square results in the model summary indicate approximately $64 \%$ of the academic performance of students' has been explained by the predictors or independent variables. The ANOVA in Table 7 indicates the overall significance of the model with $\mathrm{F}(9,304)=62.63$ and $\mathrm{P}$ value less than 0.05 .

Table 7: AVOVA Table for Overall Significance

\begin{tabular}{llccccc}
\hline & Model & Sum of Squares & $\boldsymbol{d} \boldsymbol{f}$ & Mean Square & $\boldsymbol{f}$ & $\boldsymbol{p}$ \\
\hline 1 & Regression & 19.007 & 9 & 2.112 & 62.630 & $.000^{\mathrm{b}}$ \\
& Residual & 10.251 & 304 & .034 & & \\
& Total & 29.258 & 313 & & & \\
\hline
\end{tabular}

Note: a. Dependent Variable: Academic Performance measured in CGPA

b. Predictors: (Constant), mean score of factor 3, Academic Study Hours, mean score of factor 2, Sleeping Duration of Students, Monthly Family Income, Male or Female, S.S.C result , mean score of Factor 1, H.S.C result

4.4.1 Hypotheses Testing through Regression Analysis

Table 8: Regression result for item wise significance

\begin{tabular}{lccccc}
\hline \multicolumn{1}{c}{ Variables } & $\boldsymbol{\beta}$ & $\boldsymbol{S E}$ & $\boldsymbol{t}$ & $\boldsymbol{p}$ & $\mathbf{9 5 \%} \boldsymbol{C I}$ \\
\hline (Constant) & 1.784 & .285 & 6.27 & .000 & {$[1.224,2.345]$} \\
Male or Female & -.085 & .022 & -3.88 & $.000^{*}$ & {$[-.129,-.042]$} \\
S.S.C result & .084 & .060 & 1.39 & .166 & {$[-.035, .202]$} \\
H.S.C result & .115 & .041 & 2.82 & $.005 *$ & {$[.035, .194]$} \\
Monthly Family Income & .006 & .009 & .62 & .536 & {$[-.012, .024]$} \\
Sleeping Duration & .025 & .012 & 2.16 & $.032 *$ & {$[.002, .048]$} \\
Academic Study Hours & .277 & .016 & 17.19 & $.000^{*}$ & {$[.245, .309]$} \\
mean score of Factor 1 & -.013 & .013 & -1.04 & .300 & {$[-.038, .012]$} \\
mean score of factor 2 & -.007 & .010 & -.69 & .493 & {$[-.028, .013]$} \\
mean score of factor 3 & .024 & .014 & 1.79 & .075 & {$[-.002, .051]$} \\
\hline
\end{tabular}

Note: 1. Dependent Variable: Academic Performance measured in CGPA

2. ** and * indicates $\mathrm{p}$-value is significant at $1 \%$ and $5 \%$ level, respectively

3. CI implies confidence interval

The derived results of multiple linear regression results indicate that p-value based on gender is significant at $1 \%$ level implies a large variation in performance of male and female students. Hence, our hypothesis $\left(\boldsymbol{H}_{1}\right)$ of no relationship between gender and academic performance has been rejected. The results also suggest that variation exists at $1 \%$ level of significance based on higher secondary results of the respondents. Hence, our null hypothesis $\left(\boldsymbol{H}_{2}\right)$ has been rejected based on the HSC result. But, the derived result based on the SSC result does not vary significantly and hence failed to reject the hypothesis. The results indicate that tertiary level performance is positively related to secondary academic results. The sleeping duration of students also has a positive effect on academic performance and it is significant at 5\% level of significance and hence, rejects the hypothesis $\left(\mathrm{H}_{4}\right)$ that sleeping duration has no relation with performance. Academic study hour is significant at $1 \%$ level and indicates positive variation which implies that students who study more are performing well. Hence, we reject the hypothesis $\left(\boldsymbol{H}_{5}\right)$ that there is no relation between academic study hours and performance. The derived results do not indicate significant variations for other factors under study. Hence we failed to reject other hypotheses at $5 \%$ level of significance.

\section{Conclusion and Implications}

The study investigated the factors or predictors of academic performance of university students in Bangladesh in considering the socio-economic, demographic, institutional, and individual variables related to academic performance. The researchers found that conventional examination system and teachers' evaluation system is the dominant factor which is responsible for the poor performance of the students. The study also reveals that the poor financial condition of the students negatively affects their performance. Social media affiliation, part-time job, extra-curricular activities also dictate academic performance. It is notable to see that, HSC examination grades, sleeping duration, academic study hours have a significant positive influence on academic performance. 
The study findings will be of immense help for the policymakers and tertiary level think-tank to shape education strategy depending on the derived dominant factors of the study. The teachers and university authorities, parents, and students at the university level can take appropriate measures to increase the performance of the students. The research has been conducted based on a sample of one sub-urban university in Bangladesh. Further research can be conducted considering samples from different tertiary level educational institutions from different areas throughout the country considering different socio-economic context and the variables which have not been covered in this research.

\section{References}

Ahmmed, M. M. and Salim, Z. R. (2018). Determinants of Academic Performance of Undergraduate Students in Private Universities in Bangladesh: A Case Study, Global Journal of Human-Social Science: G Linguistics \& Education, 18(11), 28-34.

Ainscow, M., Booth, T., Dyson, A., Farrell, P., Frankham, J., Gallannaugh, F., \& Smith, R. (2006). Improving schools, developing inclusion. London, England: Routledge.

Alam, M. M., Billah, M. A. and Alam, M. S. (2014). Factors Affecting Academic Performance of Undergraduate Students at International Islamic University Chittagong (IIUC), Bangladesh. Journal of Education and Practice, 5(39), 143-154.

Alhajraf, N. \&. Alasfour, A. M. (2014). The Impact of Demographic and Academic Characteristics on Academic Performance. International Business Research, 7(4), 92-100.

Ali, N., Jusoff, K., Ali, S., Mokhtar, N. and Salamt, A. S. A. (2009). The Factors Influencing Students' Performance at Universiti Teknologi MARA Kedah, Malaysia. Canadian Research \& Development Center of Sciences and Cultures, 3(4), 91-90.

Ali, S., Haider, Z., Munir, F., Khan, H., \& Ahmed, A. (2013). Factors Contributing to the Students Academic Performance: A Case Study of Islamia University Sub-Campus. American Journal of Educational Research, 1(8), 283-289.

AL-Mutairi, A. (2011). Factors Affecting Business Students' Performance in Arab Open University: The Case of Kuwait. International Journal of Business and Management, 6 (5), 146-155.

Arora, N. \& Singh, N. (2017). Factors Affecting the Academic Performance of College Students. $i$-manager's Journal of Educational Technology, 14(1), 47-52.

Bartlett, M.S. (1954). A Note on the Multiplying Factors for Various Chi Square Approximations. Journal of the Royal Statistical Society, 16, 296-298.

Celestine, A. U. \& Nonyelum, O. F. (2018). Impact of Social Media on Students' academic Performance. International Journal of Scientific \& Engineering Research, 9(3), 1454-1462.

Considine, G. \& Zappala, G. (2002). Influence of social and economic disadvantage in the academic performance of school students in Australia. Journal of Sociology, 38 (2), 129-148. DOI: $10.1177 / 144078302128756543$

Demir, C. E. (2009). Factors influencing the academic achievement of the Turkish urban poor, International Journal of Educational Development, 29(1), 17-29.

Eamon, M. K. (2005). Social-Demographic, School, Neighborhood, and Parenting Influences on the Academic Achievement of Latino Young Adolescents. Journal of Youth and Adolescence, 34(2), 163-175.

Farooq, M. S., Chaudhry, A. H., Shafiq, M. and Berhanu, G. (2011). Factors Affecting Students' Quality of Academic Performance: A Case of Secondary School Level, Journal of Quality and Technology Management, 7(2), 01-14.

Gorhe, M. (March, 2019). Impact of Social Media on Academic Performance of Students. Technical Report, DOI: $10.13140 /$ RG.2.2.21427.27687.

Hijazi, S. T. and Naqvi, S.M.M. R. (2006). Factors Affecting Students Performance: A Case of Private Colleges. e-Journal of Sociology, 3(1), 1-10.

Hudley, C., \& Duran, R. (2013). Urban schools and adolescent development. In G. L. Creasey \& P. A. Jarvis (Eds.), Adolescent development and school achievement in urban communities: Resilience in the neighborhood (pp. 115-127). New York, NY: Routledge.

Kaiser, H.F. (1970). A second generation little jiffy. Psychometrika, 35, 401-415. http://dx.doi.org/10.1007/BF02291817

Kelly, W., Kelly, K., \& Clanton, R. (2001). The relationship between sleep length and grade-point average among college students. College Student Journal, 35, 84-87.

Mensah, S. O., \& Nizam, I. (2016), The Impact of Social Media on Students' Academic Performance- A Case of Malaysia Tertiary Institution, International Journal of Education, Learning and Training, 1(1), 14-21.

Mohamed, A. A., Dahie, A. M. \& Warsame, A. W. (2018). Factors Affecting Student Academic Performance: Case Study from University of Somalia in Mogadishu-Somalia, IOSR Journal of Humanities and Social Science (IOSR-JHSS), 23(3), 73-80. 
Mushtaq, I., \& Khan, S. N. (2012). Factors Affecting Students' Academic Performance, Global Journal of Management and Business Research, 12(9), 16-22.

Nayebzadeh, S., Dehnavi, H. D., Nejad, M. S., \& Sadrabadi, M. M. M. (2013). Factors Affecting the Academic Improvement of Accounting Students in Islamic Azad University of Yazd. International Journal of Academic Research in Economics and Management Sciences, 2(4), 231-243.

Olufemioladebinu, T., Adediran, A. A. and Oyediran, W. O. (2018). Factors Influencing the Academic Achievement of Students' in Colleges of Education in Southwest, Nigeria, Journal of Education and Human Development, 7(3), 109-115.

Pedrosa, R. H. L., Dachs, J. N. W., Maia, R. P., Andrade, C. Y. \& Carvalho, B. S. (2006). Educational and socioeconomic background of undergraduates and academic performance: consequences for affirmative action programs at a Brazilian research university. Conference proceedings, Paris, Retrieved from https://www.comvest.unicamp.br/paais/artigo2.pdf.

Prabhakaran, P. \& Suresh, B. (2020). Students' Perception of Socioeconomic Status and their Academic Performance. Journal of the Social Sciences, 48(3), 3307-3317.

Raley, H., Naber, J., Cro ss, S. and Perlow, M. (2016). The Impact of Duration of Sleep on Academic Performance in University Students. Madridge J Nurs, 1(1), 11-18. doi: 10.18689/mjn-1000103

Raychaudhuri, A., Debnath, M., Sen, S., \& Majumder, B. G. (2010). Factors Affecting Students' Academic Performance: A case study in Agartala Municipal Council Area, Bangladesh e-Journal of Sociology, 7(2), $34-41$.

Sakız, H., \& Aftab, R. (2019): Academic achievement and its relationships with psychological resilience and socio-demographic characteristics, International Journal of School \& Educational Psychology, 7(4), 263273. https://doi.org/10.1080/21683603.2018.1446372

Shifeng, Li., Qiongying, Xu., Ruixue, Xia. (2020). Relationship between SES and Academic Achievement of Junior High School Students in China: The Mediating Effect of Self-Concept. Frontiers in Psychology, 10:2513, 1-7. doi: 10.3389 /fpsyg.2019.02513

Singh, S. P., Malik, S., \& Singh, P. (2016). Factors Affecting Academic Performance of Students. PARIPEX INDIAN JOURNAL OF RESEARCH, 5(4), 176-178.

Tastan, S. B., Davoudi, S. M. M., Masalimova, A. R., Bersanov, A. S., Kurbanov, R. A., Boiarchuk, A. V. and Pavlushin, A. A. (2018)., The Impacts of Teacher's Efficacy and Motivation on Student's Academic Achievement in Science Education among Secondary and High School Students, EURASIA Journal of Mathematics, Science and Technology Education, 14(6), 235-2366.

Yinusa, M. A., \& Basil, A. O. (2008). Socio- Economic Factors Influencing Students' Academic Performance in Nigeria: Some Explanation from a Local Survey, Pakistan Journal of Social Sciences, 5(4), 319-323. 